\title{
Desapropiación del discurso y apertura enunciativa en "Cuando los ángeles juegan a la suiza"
}

Guillermo González Campos

\section{Consideraciones preliminares}

Uno de los rasgos más sobresalientes de la literatura contemporánea es la autoconciencia. En la actualidad, el proceso creador se ve influencia do por los conceptos que se producen sobre el fenómeno literario en los ámbitos académicos. En este sentido, como lo señala Amoretti (1995) a propósito del concepto de intertextualidad, la teoría literaria se ha convertido no solo en un espacio para reflexionar sobe el fenómeno de la escritura, sino que constituye un valioso recurso para los creadores, quienes, gracias a este tipo de conocimiento, disponen explicita y concientemente de diversas estrategias que se juegan en el proceso de la textualización.

Para Amoretti, tal situación está vinculada estrechamente con la postmodernidad y envuelve una autocrítica 
que busca demoler la autoridad del discurso monológico y oficial:

Es una literatura autoconsciente (cocinada/cruda), autorreflexiva, una literatura que tiene su origen en los seminarios universitarios y les vuelve a proporcionar a estos material para análisis e investigación.

'Poetae docti' modernos que producen textos literarios y textos críticos al mismo tiempo, que reflexionan unos sobre otros. Una especie de metatexto que intenta destruir la distinción entre discurso poético y discurso teórico. (Amoretti1996: 12).

La novela de Alfonso Chacón Cuando los ángeles juegan a la suiza (2003) se enmarca dentro del contexto descrito anteriormente y confirma la renovación de las prácticas literarias costarricense que se ha venido dando desde finales del siglo anterior. En efecto, esta novela introduce una ruptura en las técnicas narrativas tradicionales $y$, de esta manera, se enmarca dentro de una tradición de transgresión iniciada en Costa Rica a finales de la década de los sesenta por Carmen Naranjo y Rima de Vallbona y continuada, sobre todo, por la narrativa de Virgilio Mora.

Hasta ahora, la crítica se ha centrado en señalar que esta novela presenta un ambiente social dominado por el materialismo, la superficialidad y la hipocresía con el propósito de evidenciar el mundo degradado que vive la clase política y religiosa en Costa Rica. Además, ha llamado la atención sobre la incorporación de múltiples lenguajes, los cuales provienen de diversos estratos sociales, con el fin de desacreditar la pretendida uniformidad de la sociedad costarricense. En este sentido, la obra pretende utilizar el poder impugnador del lenguaje para develar los contrastes entre el ser y el parecer patentes en la vida de los personajes. Benedicto Víquez Guzmán, el único que ha abordado críticamente esta novela, ha resumido este escenario de la 
siguiente manera:

La novela se convierte en un gran espejo, no solo el del cuarto de Luci, donde se ve desnuda Aurora y comienza su descubrimiento erótico, su intimidad que posiblemente le lleve a la libertad, al final de la obra. Toda ella es un espejo donde se refleja, se delata la parte oculta del ser, la otra mitad, la otra cara de los personajes-símbolos y de la ciudad como espacio ocupado por ellos. (Víquez Guzmán 2004: 234

Sin embargo, consideramos que, más allá de mostrar la vida de apariencia que llevan los diversos personajes, la obra, gracias al conocimiento de la teoría literaria, impugna el paradigma de escritura imperan te. Además, creemos que dicha impugnación está en consonancia con la búsqueda, emprendida por algunos personajes, de una existencia auténtica, libre de la prisión de los convencionalismos sociales. En otras palabras, la novela, dentro del contexto literario costarricense, innova al introducir una desapropiación del proceso de escritura cuya finalidad es el surgimiento de la autonomía enunciativa de los personajes.

\section{La desapropiación del discurso}

El viraje más significativo que presenta la novela de Alfonso Chacón es la incorporación de un espacio, que podría denominarse supernarrativo, en el cual, al margen de la historia contada, se desarrolla un enfrentamiento entre las figuras del autor y el narrador. Aunque la sola incorporación de dicho espacio resulta sumamente sugestiva, el deslinde entre el autor y el narrador es aún más llamativo, pues suscita una ruptura dentro del orden lineal de construcción novelística e introduce la noción de otredad dentro de un espacio narrativo que tradicionalmente ha estado ocupado por una figura individual. 
Debe considerarse aquí que las figuras de autor y narrador, aunque pertenecientes a ámbitos conceptuales diferentes, han sido asimiladas como contrapartes de una misma entidad; es decir, en las obras narrativas el autor se constituye en sujeto de la enunciación. En palabras de Kristeva (1978: 203), "el autor es, pues, el sujeto de la narración metamorfoseado porque se ha incluido en el sistema de la narración". Dicho de otra forma, el autor deja de ser persona y se transforma en una posibilidad, en un ente de ficción del discurso narrativo!

Por eso, la consecuencia primordial de la disociación de la que estamos hablando es la inserción del concepto bajtiniano de dialogismo en un ámbito que, hasta ahora, había estado dominado por una voz única, absoluta e incuestionable, es decir, por una voz monológica. Al respecto, es importante tener en cuenta que el dialogismo se había asumido como la incorporación de diversas voces que viven en contigüidad sin fusionarse, es decir, un polivocalismo en el que tanto la voz ajena como la propia tienen igual valor y cuyo último propósito es derribar a su contrapartida, el monologismo que busca reducir el potencial de las diversas voces a una sola voz de autoridad. Chávez (2001) caracteriza esta situación de la siguiente forma:

Lo dialógico concierne a la interacción entre los sujetos parlantes. Supone, a la vez, una articulación que incorpora las voces del pasado, la cultura y la comunidad. En definitiva, revela la orientación social del enunciado. En tanto determina pluralidad y otredad, se opone a la voz monológica que impone el discurso del poder: la norma y la autoridad. Hacerse portador de la dialogia significa el desafío a este lenguaje único.

\footnotetext{
${ }^{1}$ Por eso, uno de los aspectos en los que más insistió la crítica estructuralis ta fue en la necesidad de hacer una separación entre ambos conceptos. Tal fue el propósito de Barthes (1974: 33) al escribir: "... el autor (material) de un relato no puede confundirse para nada con el narrador de ese relato; los signos del narrador son inmanentes al relato y por lo tanto, perfectamente accesibles al análisis semiológico."
} 
Desde el punto de vista narrativo, la introducción de la dialogicidad conlleva una disminución en el protagonismo en la visión y la voz del autor y un aumento en la relevancia de los personajes, los cuales obtienen una autoconciencia que les permite juzgar el mundo desde ellos y para ellos. Mijail Bajtín (1988: 80), al comentar los rasgos estilísticos de la obra de Dostoievski que sus contemporáneos no lograban comprender, lo puso en los siguientes términos: "El autor efectivamente le deja la última palabra a su héroe. [...] El héroe en Dostoievski no es una imagen objetivada sino la palabra plena, la voz pura; no lo vemos, pero lo oímos..." Sin embargo, en "Cuando los ángeles juegan a la suiza", el dialogismo no solo se da en el ámbito descrito anteriormente, sino que trasciende este nivel al presentar al autor y al narrador como entidades distintas, lo cual implica llevar la dialogicidad al ámbito supernarrativo, en el que supuestamente se genera el discurso.

Ahora bien, esta ruptura se vuelve aún más subversiva si tomamos en cuenta que tradicionalmente la noción de autor ha estado vinculada con el acto de la "creación" del texto y, por ende, también con el proceso de su apropiación y legitimación. Por eso, no es posible desligar este término del conjunto de significaciones que su etimología le conlleva: el término autor está relacionado con la palabra latina auctus, participio pasado del verbo augere, cuya red de significados se teje en torno a las nociones de desarrollo, progreso y acrecentamiento. Auctor no es un simple sinónimo de artifex o faber, pues no se limita a producir, inventar sino que, además, ejerce un "derecho de posesión" sobre sus obras. De ahí su vinculación con auctoritas, que se refiere tanto al prestigio que garantiza la ejemplaridad de una persona como al acto de inventar, crear, iniciar, engendrar, etc.

Precisamente, Michel Foucault (1999), en su ensayo ¿Qué es un autor?, ha puntualizado con claridad que la 
primera función del autor es la apropiación del texto, lo cual está vinculado directamente al sistema jurídico e institucional que envuelve, determina y articula el universo de los discursos. El surgimiento del régimen de propiedad de los textos, materializado hoy día en los "derechos de autor", corresponde históricamente a la necesidad de circunscribir al discurso dentro del ámbito de las propiedades con el fin de "responsabilizar" y "penalizar" a alguien por el origen de los textos:

Los textos, los libros, los discursos empezaron a tener autores (diferentes de personajes míticos, de grandes figuras sacralizadas y sacralizantes) en la medida en que el autor podía ser castigado, es decir, en la medida en que los discursos podían ser transgresivos. (Foucault 1999: 339).

Por lo tanto, la novela en cuestión, al segmentar el proceso "creador", no crea otro efecto que poner de manifiesto el aparato discursivo que ha sostenido la figura del autor, pues asigna el proceso creador al narrador y la apropiación y responsabilidad jurídica del texto al autor. En relación con lo anterior, consideremos la siguiente cita:

- iAnte todo, respeto, qué por algo soy el autor! - ¡Y yo el narrador! Y si no le cuadra, se va localizando otro, que a mi me entra flojo. De por sí, poco me estoy ganando por la menuda tarea que me ha encargado usted.

-Bueno, suave... ¡Ay, qué tipo tan pesado! Está bien, de todas formas habría de aguantarme tus quejas si contratara a otro... que más da si te dejo la pluma un poco libre. Pero tendré bien presente que el del nombre en la portada soy yo. ¡Si algo pasa, es a mí a quien encarcelan! (Chacón 2003: 12).

Se puede notar en el fragmento anterior un proceso que se inicia desde el principio de la novela y que, tras el 
desarrollo de esta, se va a ir acrecentando: la pérdida que sufre el autor del control, y por lo tanto del poder, sobre la historia que se va contando.

Desde el principio el autor se va a ver reducido a una figura meramente jurídica. Es un nombre (palabra, lenguaje) en la portada de un libro, es decir, él también forma parte del universo de los discursos. Pero es además el que debe asumir la responsabilidad ante el aparato jurídico del texto. Esto se refleja sobre todo en el constante miedo de ser penalizado que el autor siente. Sin embargo, el narrador no se preocupa por esto:

Han de disculpar las estimadas lectoras y lectores por la interrupción, pero mi patrón, autor de ínfulas y quien me trasmite la historia a través de su chismorreo inconsciente, es también de carácter apocado: no desea ver su nombre cuestionado por contar lo que no debe. Pero en fin, dónde quedaría la libertad creativa si los narradores anduviéramos con melindres tales, y ya que ustedes han comprado este libelo, pues entonces la historia completa tendrá. (Chacón 2003: 13).

De hecho, lo primero que sobresale en la novela es que el narrador es consciente tanto de su papel de ente ficcional creado para narrar una novela como de la existencia de un ser "real" escondido bajo el nombre de autor. Al respecto, considérese la siguiente cita:

Empero, antes de seguir, he de detenerme y justificar mi presencia, como narrador circunspecto que soy: lo admito, no es mía esta ficción. Alguien -llamémosle autorme ha encargado esta narración, a cambio de unos cuantos pesos y derecho a elucubrar. (Chacón 2003: 6).

Durante el desarrollo de la novela, uno de los aspectos que más sobresalen es el surgimiento de diversos conflictos entre el narrador y el autor. El origen de estos enfrentamientos son diferencias sobre la forma en que se está 
contando la historia. El autor suele mostrarse intransigente ante las libertades que el primero se toma y en ocasiones lo interpela con violencia:

Mirá... ¿Vos sabés lo que más me emputa? Que si de veras yo te preocupara me harías caso... ayer hojeé las últimas páginas... insinuaciones de corrupción, de degeneración sexual... nada menos... pero no quiero pelear con vos, estoy harto: tal vez la cárcel me dé la fama y alguien lea la basura que estás armando... (Chacón 2003: 61).

Esta relación problemática va articular la dinámica dialógica de la que hablábamos antes. El autor posee un pensamiento de tipo monológico que intenta imponer sobre el narrador, quien, conocedor de su papel dentro de la obra literaria, renuncia al carácter monológico, no acepta homologarse al autor de la novela y asume una actitud dialógica. Se presenta entonces una tensión entre el convencionalismo defendido por el autor y las innovaciones estilísticas del narrador. Obviamente cada uno busca propósitos distintos. El autor desea publicar, insertarse en el mercado editorial y ser reconocido, su fin primordial no es la historia; mientras que el compromiso del narrador es para con la historia y los lectores.

Un ejemplo de lo expuesto anteriormente se encuentra en el siguiente fragmento, en el que el autor le reclama al narrador por la desorganización que impera en la narración de la novela:

- [...] Esta novelita ya semeja un quilting mal zurcido: no hay unidad temática, se presentan hechos basados en infundios, no hay desarrollo uniforme, los personajes se pierden, la voz narrativa es prejuiciado, 
sentenciosa, sin consistencia... ¡ A ver si te decidís de una puta vez por todas cómo la vas a escribir!

- iY...! ¡Así es la vida, machillo! Dónde se ha visto que este mundo sea estructurado. Las cosas vienen así, por pedazos, descoordinadas. Si quería algo bien tramado, entonces hubiéramos hecho una novela policíaca. (Chacón 2003: 127).

El enfrentamiento entre lo monológico (autor) y lo dialógico (narrador) va a finalizar con el triunfo del segundo sobre el primero gracias a las estrategias carnavalescas. Mijaíl Bajtín (2002: 22-57) ha señalado que la cultura cómica popular engendró una serie de imágenes referentes a la vida material y corporal que platean una concepción estética de la vida práctica. A esto se le conoce con el nombre de realismo grotesco y corresponde a un principio universal y popular. El rasgo más sobresaliente del realismo grotesco es la degradación, la cual consiste en la transferencia de lo elevado, espiritual, ideal y abstracto al plano material y corporal. Esta degradación es ambivalente, pues no solo contempla un carácter negativo, sino que implica uno positivo y regenerador. En otras palabras, lo gastado es refundido y renace. Este carácter renovador del realismo grotesco le permite, además, asociar lo heterogéneo y distante. También percibe la relatividad de todo lo existente y, por eso, posibilita el cambio. En fin, su función primordial es observar el mundo de un modo diferente y nuevo. Todo esto, Bajtín lo sintetiza de la siguiente forma:

El rebajamiento es, finalmente, el principio artístico esencial del realismo grotesco: todas las cosas sagradas y elevadas son reinterpretadas en el plano material y corporal. Hemos hablado del columpio grotesco que funde el cielo y la tierra en su vertiginoso movimiento; sin embargo, el acento es puesto allí no tanto en la ascensión como en la caída: es el cielo que desciende a la tierra y no al revés. 
Todos estos rebajamientos no tienen un carácter relativo o de moral abstracta, sino que son, por el contrario, topográficos, concretos y perceptibles; se dirigen hacia un centro incondicional y positivo, hacia el principio de la tierra y del cuerpo que absorben y dan luz. Todo lo acabado, casi eterno, limitado y obsoleto se precipita hacia lo "inferior" terrestre y corporal para morir y renacer en su seno. (Bajtín 2002: 334-335).

En la novela de Alfonso Chacón, el lenguaje autoritario del autor se va desmoronar ante la burla y el escarnio que sufre por parte del narrador. Desde el inicio de la obra, este va a escarnecer a aquel, incluso lo engaña sobre el contenido y la forma de narrar de la novela, cuando llega enfermo y le solicita que le lea el final de lo que ha escrito sobre la relación entre José Antonio, el profesor de colegio, y su alumna Pilar. La satisfacción del autor ante el texto y la ironía del narrador ante el engaño no pueden ser más manifiestas:

-Me gusta, me gusta como trataste lo del noviazgo ese. Es que tomando en cuenta la diferencia de edad, se podía pensar mal.

- ¡Hombre, para eso estamos los narradores! ¡Para poner las cosas en bonito!

(Chacón 2003: 26-27).

Tras el desarrollo de la novela el papel del autor se va a ver reducido sustancialmente. Incluso, va a convertirse en víctima de un seudo crítico y maestro literario que cobra veinte mil pesos por mes por sus "sabios" consejos. Al final de la novela, prácticamente desaparece y le deja todo el espacio que hemos llamado supernarrativo al narrador (Cfr. el apartado titulado El narrador amenaza con retirarse [Chacón 2003: 269-270]). 
Esta "muerte del autor" al final de la novela, nos lleva, por supuesto, al planteamiento de Roland Barthes en su ya legendario artículo titulado precisamente La muerte del autor. Barthes, en este famoso artículo, hace una crítica profunda a la idea romántica de que el autor es el centro de la obra, pues tal consideración supone que el lector es un ser pasivo que sencillamente debe tratar de entender lo que el autor deseó comunicar. Por eso, Barthes asesina al autor con el fin de desvanecer su autonomía y permitir que esa pretendida idea fundadora del texto, si es que existe, ceda su lugar a las múltiples posibilidades que, como una red, se tejen entorno al texto; es decir, se ingresa al ámbito de lo intertextual. La idea de que hay que tratar de descifrar un texto no es más que una imposición de límites al sentido y, por lo tanto, el cierre del texto. Tras la muerte del autor se esconde el nacimiento del lector.

En consonancia con la ideas de Barthes, Foucault ha propuesto que una de las funciones del autor, en tanto que formación discursiva, persigue la restricción del carácter plurisignificativo de los textos:

El autor es el principio de economía en la proliferación del sentido. [...] Estamos acostumbrados a decir [... que el autor es la instancia creadora de la que brota una obra en la que se deposita, con una infinita riqueza y generosidad, un mundo inagotable de significaciones. [...] La verdad es completamente diferente: el autor no es una fuente indefinida de significaciones que se colmarían en la obra, el autor no precede a las obras. Existe un cierto principio funcional mediante el que, en nuestra cultura, se delimita, se excluye, se selecciona: en una palabra, el principio mediante el que se obstaculiza la libre circulación, la libre manipulación, la libre composición, descomposición 
de la ficción. [...] El autor es pues la figura ideológica mediante la que se conjura la proliferación del sentido. (Foucault 1999: 350).

El proceso de desautorización que se fragua en la novela de Alfonso Chacón busca devolverle al lector el derecho de ser un ente activo en el proceso de creación del sentido de la obra, el cual, de ningún modo, podrá considerarse estable. Por eso, no debe extrañar que el narrador en diversas ocasiones interpele a los lectores, a quienes incluso guarda cierta especie de consideración. Cuando el narrador se dirige al lector, lo hace sin especificar el género y con la finalidad de explicarle algunos aspectos de la narración de la novela. A veces, llega inclusive a justificarse. Se da la sensación de que el narrador está muy preocupado por la apreciación que el lector o lectora va teniendo tras el desarrollo de los acontecimientos novelescos. Esta íntima preocupación por la recepción del texto está patente desde el inicio de la novela, cuando el narrador "se presenta" ante los lectores. Como ejemplo de esto, valórese lo que se expresa en el siguiente pasaje:

Pero volvamos al relato: yo solo narro, no tengo importancia. Ustedes relájense, tomen un refresco, acomódense en su poltrona, y si quieren preguntar, háganlo. Al fin y al cabo, es solo una historia, y ustedes habrán escuchado mejores: les doy derecho a opinar. Por mi parte, solo digo lo que me han contado. Volvamos a la acción. (Chacón 2003: 26-27).

Lo innovador de tal técnica narrativa no se encuentra en interpelar al lector, pues esa estrategia ha sido utilizada desde hace siglos; sino que reside en manifestar consideración hacia los lectores y reconocer que ellos también 
poseen ingerencia sobre la historia. Como lo dijimos anteriormente, el compromiso del narrador se presenta con el lector, al cual le une los sentimientos de responsabilidad y obligación. De hecho, son estos sentimientos los que provocan que, a pesar de considerar que no debe seguir contando la historia, lo continúe haciendo. Tal situación es manifiestamente explícita en la siguiente cita textual:

[...] lo prometido es deuda: me he obligado a darle a usted toda la historia, con puntos y comas y, aun si mi patrón me corta el estipendio magro, merece usted saber el resto, por lo menos para que conste que este servidor cumple sus promesas. (Chacón 2003: 269. 271).

En este sentido, puede decirse que "Cuando los ángeles juegan a la suiza" es una obra abierta, a la espera de un lector que venga a construirla.

\section{Apertura Enunciativa y recuperación de la voz}

Pero esta desvinculación del autor con lo que se dice en la novela puede interpretarse de otra forma si analizamos su papel desde otra perspectiva y tomamos en cuenta el desarrollo de los hechos narrados.

En primer lugar, consideremos la diégesis de la obra. Cuando los ángeles juegan a la suiza es, básicamente, la historia de una mujer, Aurora, que ha sufrido toda su vida los embates de la ideología patriarcal. Tras una aventura, logra tomar ánimos para divorciarse de su marido e iniciar una vida independiente. El fin de su matrimonio implica por tanto la eliminación de una vida que, hasta ese momento, había estado dominada por las figuras del padre y el marido. Es decir, Aurora experimenta una liberación de los cánones 
patriarcales y un rehacerse a partir de sus propios intereses como mujer.

Sin embargo, si tomamos en cuenta que el ámbito conceptual del autor se relaciona con los fundamentos de la sociedad patriarcal en cuyo contexto se dan las prácticas discursivas, también hay que considerar que esta liberación va más allá. En efecto, como lo han hecho ver Sandra Gilbert y Susan Gubar (1998), existen una serie de conexiones entre la autoría y la paternidad que no son casuales. De hecho, en la sociedad patriarcal occidental, el autor de un texto es asimilable a un padre, a un progenitor que, como Dios Padre, engendra su propio cosmos. Dentro de este contexto, el simbolismo fálico de la pluma es totalmente claro: es un instrumento de poder generativo semejante al pene. Como lo mencionan estas autoras, las implicaciones que tal situación conlleva nos remiten a un autor que, a semejanza de un dios, es el dueño y señor de sus entes creados:

[...] el hecho de que dicha noción de "posesión" esté imbuida en la metáfora de la paternidad conduce a otra implicación más de esta compleja metáfora. Porque si el autor/padre es el dueño de su texto y de la atención de su lector, también es dueño/poseedor de los sujetos de su texto, es decir, de esas figuras, escenas y hechos -esas criaturas de la mente- que ha encarnado en blanco y negro y "encuadernado" en tela o cuero. (Gilbert y Gubar 1998: 21)

Así pues, el hecho de que el autor, que en esencia es masculino, sea el propietario de la historia de Aurora deja ver que la liberación que esta busca no solo debe darse dentro de la historia, sino que debe trascender al nivel donde se produce el discurso. La lucha de Aurora no es solo por lograr su autonomía como persona, sino también por el 
derecho a decirse, por el derecho de contarse a sí misma, lo cual logra al final de la novela cuando el autor ya no se oye, cuando el proceso de des apropiación ha llegado a su culminación con el silencio de la palabra enajenante.

El narrador es una figura importante en este proceso. Él se sabe poseedor de un privilegio especial (contar) y, en lugar de promover una marginación de las restantes voces de la obra, lo cual él sabe que puede hacer, busca promover el surgimiento de conciencias independientes de la del autor en los personajes e, incluso, como hemos visto antes, en los lectores. En relación con esto, resulta relevante traer a colación la interacción comunicativa que es asumida por el narrador, la cual es, en sí misma, contradictoria. En efecto, resulta sumamente discordante que el narrador, siendo un narrador omnisciente, interactúe con los personajes de la novela, atribución exclusiva de otro tipo de narradores.

Es necesario aclarar aquí que el concepto de narrador pertenece al campo de lo nocional. En efecto, el narrador es una construcción teórica del estructuralismo creada por la necesidad de enfrentarse al texto por medio del principio de inmanencia. Sin embargo, es bueno recordar que esta noción no estuvo exenta de polémica. En su retrospectiva sobre las visiones teóricas acerca del narrador, Margery (1975) ha señalado que lo único seguro sobre este concepto es la presencia de una gran diversidad de criterios. Sin embargo, también recalca que sobresale el hecho de que existe unanimidad en reconocer la existencia de un narrador que cuenta en "tercera persona omnisciente". Este narrador es caracterizado de diversas formas por los teóricos: "un gran pájaro que vuela sobre sus personajes" (Andrés Amorós), "un autor dios que todo lo sabe" (Óscar Tacca), "un demiurgo, un espectador privilegiado" (Jean Pouillon), "un dios olímpico" (Konrad Kurz). 
Este único consenso en medio de tanta discordancia no resulta para nada extraño si tenemos en cuenta que es precisamente el narrador omnisciente el que tradicionalmente se ha identificado con el autor. Precisamente, existe un cierto tipo de novelas en las que solo se oye al autor de la narración y este, a su vez, no se distingue del sujeto de la enunciación (el narrador). Este tipo de obras corresponden a una concepción del mundo lineal, sistemática, que hace que el texto permanezca codificado bajo una conciencia moral, teológica y logocéntrica unívoca. Como se dijo antes, el narrador de estas novelas conoce toda la historia y tiene un punto de vista privilegiado, ya que puede apreciar, evaluar y comprender hechos y acontecimientos. En palabras de Kristeva (1974: 126), en estas obras "el discurso narrativo, que asimila al discurso épico, constituye una prohibición, un monologismo, una subordinación del código al 1, al Dios."

En clara confrontación con ellas, se encuentra la novela polifónica, la cual se caracteriza por la desaparición del héroe, la experimentación con el tiempo y la ilogicidad. En ellas, hay un descubrimiento del otro, lo que conlleva la desaparición del narrador "olímpico" que lo sabe todo.

En la novela en cuestión, el narrador desea experimentar con esta estructura y no vacila en sacrificarse él mismo con tal de lograr su cometido. En otras palabras, el narrador renuncia conscientemente a su mirada privilegiada, a su posición olímpica en aras de permitir a otros sujetos hablantes la articulación de sus voces. En abierta contraposición con el monologismo, no permite que el potencial de voces se reduzca a la suya.

El narrador, consciente de su propia omnisciencia, también es consciente de que esta es solo un efecto narrativo. Considérese al respecto lo que dice en la siguiente cita: 
Ahora desviémonos un poco. Saltemos al hiperespacio narrativo gracias al ardid de la omnisciencia (y de la cercanía propia de este San José de cortas distancias). Rompamos la unidad narrativa y dejemos a Aurora cumpliendo con las variadas obligaciones espirituales y domésticas que la sociedad - ¡ay, terrible artilugio síncrono e imparable!- impone al individuo femenino, mientras, no tan lejos, Arturo se encarga de las tareas profesionales: labrar su destino glorioso... (Chacón 2003: 74).

Por eso, en clara confrontación con este carácter, el narrador mantiene conversaciones con algunos de los personajes. En el inicio de la novela, por ejemplo, va a visitar a Pilar y recoge su testimonio directo por medio de una grabadora. Luego, durante la misa dominical, conversa con el cuidador de carros de la Iglesia. Pero el mejor ejemplo de esto, es cuando narra el encuentro entre Mariana, la amante de Arturo, y Aurora. La siguiente cita evidencia tal situación:

Y por fin, henos aquí. A trancadas hemos saltado los escalones, antes que su majestad, todavía ocupado en sus avatares en el estacionamiento del edificio, nos dé alcance. Orlando, momentos antes, cuando la dulce Mariana aún hacía espera intranquila en el sofá de la recepción, había sentido la llegada de Aurora en el tono cortés de Ruth. Fue un súbito impulso el que lo hizo levantarse de su escritorio para acudir de inmediato al salón de espera. La rubia de piernas admirables, que hacía rato aguardaba por don Arturo, desaparecía por la puerta principal (y yo detrás, lo admito) al mismo tiempo que Orlando alcanzaba el salón. (Chacón 2003: 184).

Una cualidad que está asociada a la omnisciencia es la ubicuidad; sin embargo, en la cita anterior, el narrador 
de esta novela reconoce que no puede estar en dos lugares al mismo tiempo y debe dejar a Mariana para volver a la oficina de Arturo y "ver" que pasó. Tal parece que el narrador es un dios que no desea asumir su papel. Asimismo, en una parte determinada de la novela, el narrador cambia su estrategia de contar y se dirige directamente a Aurora, el personaje principal de su historia, y le habla en un tono dulce y paternal

Ibas casi dormida al salir del té: tu mente, en múltiples capas de sueños inconexos, rumiaba el neblinoso placer letárgico de la ensoñación. Por eso el enojo con Arturo, la frustración de comprobar su olvido imperdonable para con tu natalicio... (Chacón 2003: 65).

Y hoy, jueves, Aurora, te había amanecido nublado el ánimo de nuevo, como una mañana de noviembre en los alrededores de los docks victorianos que tanto gustaba de pintar Monet... (Chacón 2009: 65).

Pero no solo es el narrador el que busca la comunicación, sino que algunos personajes son conscientes de su existencia y se comunican con él de forma escrita. Sobresalen en este aspecto el correo electrónico que Pilar le envía con el objetivo de aclararle algunos acontecimientos y solicitarle que deje en paz a Aurora. Además, también puede darse como ejemplo la carta que la misma Aurora le envía al final de la novela. Llama la atención que ante ellas el narrador queda como una metiche, un entrometido que se inmiscuyó sin permiso en la vida de las personas.

Todo esto muestra que en la novela se opera un rebajamiento de la figura del narrador, pues, este, en lugar de ocupar una posición privilegiada, donde puede observarlo y juzgarlo todo, es reducido al papel de un ente ficcional 
más de la novela, una mera estrategia discursiva que se usa para contar una historia.

Ahora bien, ¿cuál es el resultado concreto de la desaparición del autor y el rebajamiento del narrador? La respuesta es clara: hay un surgimiento de las diversas voces de los personajes. Con respecto a esto, es relevante observar que la novela presenta un apartado titulado Coro descoordinado y tragicómico (págs. 202-208), en el que se hace palpable de manera ostensible y abierta el fenómeno de la polifonía.

Efectivamente, a lo largo del relato se incorporan una gran cantidad de voces, la gran mayoría provenientes del Valle Central. Los estratos sociales a los que pertenecen estas voces son variados. Unos personajes pertenecen a los estratos sociales bajos (las sirvientas, los guardas, los trasvestis, por ejemplo), mientras que otros se desenvuelven en un mundo de clase alta (Arturo, Aurora y sus familiares y amigos, claro está). No falta en la novela la referencia a la clase media emergente (Orlando) y al orden sacerdotal (el padre Gonzalo, por ejemplo). Finaliza esta diversidad la incorporación de ejemplos de personajes mediáticos (el padre Mayor, G. Villaverde).

No obstante, no se puede dejar de observar que, como lo han señalado lo comentarios previos al nuestro, esta amalgama de voces, aunque poseedoras de una pluralidad, se conjugan en un (des\}concierto con el fin de desenmascarar la vida llena de convencionalismos que llevan los diversos personajes.

Tal es el caso particular de Aurora, quien al final logra tomar la palabra y dar su versión de los hechos por medio de una Carta de despedida o de epitafio. He ahí la recuperación de la palabra: se cuenta la historia desde la perspectiva femenina, con voz propia, y no desde la perspectiva masculina del autor, el cual a lo largo de la obra va perdiendo protagonismo hasta que finalmente desaparece, 
o del narrador, quien consciente de su papel ficticio va cediendo terreno a las restantes voces.

\section{Consideraciones finales}

En la novela "Cuando los ángeles juegan a la suiza" no solo se halla una denuncia de la dicotomía entre el ser y el parecer que sufren los personajes por culpa de los convencionalismos sociales que agobian a la sociedad costarricense de principios de siglo. La obra va más allá, pues impugna el status qua en su punto más susceptible: el proceso de la validación y legitimación de los discursos. Es decir, reacciona ante una manera excluyente y enajenante de contar una historia.

La incorporación de un espacio supernarrativo en el cual se da una lucha por decir la historia devela las relaciones de poder que se juegan en el 1 / proceso de generación discursiva e impugna el discurso autoritario que los centros de poder utilizan para dominar el espacio comunicativo.

Así, en la novela, aspectos como la desapropiación del texto, la degradación del autor, el rebajamiento del narrador, la necesidad de considerar el punto del vista del lector, la incorporación de diversas voces que terminarán abarcando el mundo discursivo con simultaneidad no persiguen otro objetivo que reivindicar discursos alternos marginados o eliminados con el fin de hacer ver la lucha que se da por recuperar la palabra.

\section{Bibliografía}

Amoretti, María. 1992. Diccionario de términos asociados en teoría literaria. San José, C. R.: EUCR.

Amoretti, María. 1995. "Tres niveles intertextuales por los seis lados del cubo de la escritura" .Kánina, XIX (1): 15-18. 
Amoretti, María. 1996. "La intertextualidad: Un ensayo metacrítico". Revista de Filología y Lingüística de la Universidad de Costa Rica, XXII (2): 714.

Bajtín, Mijaíl. 1986. Problemas literarios y estéticos. La Habana: Editorial Arte y Literatura.

Bajtín, Mijaíl. 1988. Problemas de la poética de Dostoievski. México: Fondo de Cultura Económica. Bajtín, Mijaíl. 1989. Estética de la creación verbal. México: Siglo XXI. Barthes, R., A. J. Greimas et al. (eds.). 1974 Análisis estructural del relato. Buenos Aires: Editorial Tiempo Contemporáneo.

Barthes, Roland. 1974. "Introducción al análisis estructural de los relatos". En R. Barthes, A. J. Greimas et al. (eds.), 9-43.

Barthes, Roland. 1987. "La muerre del autor". En El susurro del lenguaje. Barcelona: Paidós.

Chacón, Alfonso. 2003. Cuando los ángeles juegan a la suiza. . San José, C. R.: EUCR.

Chávez, Melina. 2001. "Tres apuntes sobre teoría literaria". Consultado el 6 de julio del 2005 en http://www.salvador.edu.ar/gramma/ 3/ual-7-gramma-O1-03-11.htm.

Foucault, Michael. 1999. “QQué es un autor?”. En Entre filosofía y literatura. Obras esenciales, Volumen 1. Barcelona: Paidós.

Gilbert, Sandra M. y Susan Gubar. 1998. La loca del desván. La escritora y la Imaginación literaria del siglo XIX. Madrid: Cátedra.

Kristeva, Julia 1974. El texto de la novela. Madrid: Lumen.

Kristeva, Julia. 1978. Semiótica 1. Madrid: Fundamentos.

Margery Peña, Enrique. 1975. "Alcances en torno a la problemática del narrador". Revista de Filología y Lingüística de la Universidad de Costa Rica, I (1): 55-82.

Quesada Soto, Álvaro. 2000. Breve historia de la literatura costamicense. San José, C. R.: Editorial Porvenir.

Trottier, Daniéle. 1993. Juego textual y profanación. San José, C. R.: EUCR.

Víquez Guzmán, Benedicto. 1986. Cómo leer novelas. San José, C. R.: Editorial Nueva Década.

Viquez Guzmán, Benedicto. 2004. Las generaciones de los novelistas costarricenses (Volumen 111). Heredia: Editorial Nanzug.

Zavala Zapata, Iris. 1991. La pos modernidad y Mijail Bajtín: Una poética dialógica. Madrid: Espasa Calpe. 